\title{
Molybdenum metabolism in plants and crosstalk to iron
}

\author{
Florian Bittner* \\ Department of Plant Biology, Braunschweig University of Technology, Braunschweig, Germany
}

\section{Edited by:}

Felipe Klein Ricachenevsky, Universidade Federal do Rio Grande do Sul, Brazil

Reviewed by:

Ruediger Hell, University of Heidelberg, Germany

Markus Wirtz, Centre for Organismal Studies, Germany

\section{*Correspondence:}

Florian Bittner, Department of Plant Biology, Braunschweig University of Technology, Spielmannstrasse 7, 38106 Braunschweig, Germany e-mail:f.bittner@tu-bs.de
In the form of molybdate the transition metal molybdenum is essential for plants as it is required by a number of enzymes that catalyze key reactions in nitrogen assimilation, purine degradation, phytohormone synthesis, and sulfite detoxification. However, molybdate itself is biologically inactive and needs to be complexed by a specific organic pterin in order to serve as a permanently bound prosthetic group, the molybdenum cofactor, for the socalled molybdo-enyzmes. While the synthesis of molybdenum cofactor has been intensively studied, only little is known about the uptake of molybdate by the roots, its transport to the shoot and its allocation and storage within the cell. Yet, recent evidence indicates that intracellular molybdate levels are tightly controlled by molybdate transporters, in particular during plant development. Moreover, a tight connection between molybdenum and iron metabolisms is presumed because (i) uptake mechanisms for molybdate and iron affect each other, (ii) most molybdo-enzymes do also require iron-containing redox groups such as iron-sulfur clusters or heme, (iii) molybdenum metabolism has recruited mechanisms typical for iron-sulfur cluster synthesis, and (iv) both molybdenum cofactor synthesis and extramitochondrial iron-sulfur proteins involve the function of a specific mitochondrial ABC-type transporter.

Keywords: aldehyde oxidase, iron, molybdenum, molybdate transporter, molybdo-enzymes, nitrate reductase, sulfite oxidase, xanthine dehydrogenase

\section{INTRODUCTION}

Molybdenum is a transition metal, which occurs in the lithosphere at an average abundance of $1.2 \mathrm{mg} \mathrm{kg}^{-1}$ and represents one of the scarcest trace elements in biological systems (Kaiser et al., 2005). In the soil, molybdenum exists predominantly in the form of the oxyanion molybdate, which serves as an essential micronutrient in all kingdoms of life. Yet, molybdate alone does not exhibit biological activity, but is bound to an organic pterin backbone, which upon binding of molybdate is converted into the molybdenum cofactor (Moco). Once being incorporated as prosthetic group, Moco becomes part of the active site of molybdo-enzymes, where molybdenum can vary its oxidation state between $\mathrm{Mo}(\mathrm{IV}), \mathrm{Mo}(\mathrm{V})$, and $\mathrm{Mo}(\mathrm{VI})$, thereby enabling the respective protein to transfer electrons, and in most cases also oxygen, from or to a substrate (Hille, 2013). Due to its special importance for plants, another molybdenum-containing cofactor exclusively found in certain bacteria is mentioned. This cofactor is part of the unique enzyme nitrogenase that catalyzes the fixation of nitrogen by reduction of atmospheric $\mathrm{N}_{2}$ to $\mathrm{NH}_{3}$ in free-living, but also symbiotic bacteria in the nodules of legumes (Kneip et al., 2007). Unlike Moco however, the nitrogenase cofactor is constituted of molybdenum ligated to a complex iron-sulfur cluster and homocitrate and therefore is named FeMoco (Hu and Ribbe, 2013).

In soil, a critical point concerns the bioavailability of molybdate, which is favored above $\mathrm{pH} 5.5$ and impaired at lower $\mathrm{pH}$ due to the adsorption of molybdate to soil oxides (Kaiser et al., 2005). Under low-pH conditions, molybdate assimilation is therefore limited resulting in molybdenum deficiency associated with reduced molybdo-enzyme activities and reductions in plant growth and yield. Fortunately, this type of molybdenum deficiency can be compensated by fertilization with molybdate or by increasing the soil $\mathrm{pH}$ by liming. In contrast, molybdenum toxicity by oversupply of plants with molybdate is extremely rare and characterized by relatively mild symptoms such as yellowish leaves (Kaiser et al., 2005) or reduced seedling growth and increased anthocyanin concentrations (Kumchai et al., 2013).

In consideration of the present knowledge of molybdate uptake, transport and storage, the specific functions of the molybdenum-dependent enzymes and the interrelation between molybdenum and iron, this review focuses on the current understanding of the molybdenum homeostasis network in plants and points to some hitherto unidentified factors (Table 1; Figure 1).

\section{UPTAKE, TRANSPORT, AND STORAGE OF MOLYBDATE}

Early in plant molybdenum research Kannan and Ramani (1978) described the active uptake of exogenously applied molybdate by roots and its transport to the shoot. However, molybdate levels reached a maximum in the shoot already $6 \mathrm{~h}$ after application, indicating that uptake of molybdate and sensing of intracellular molybdate levels are well controlled processes. Notably, when molybdate is applied solely to leaves transport also occurs downward to the stem and roots, demonstrating that molybdate is a highly mobile compound translocated between various plant tissues. Furthermore, the finding that sulfate is a potent inhibitor of molybdate uptake (Stout etal., 1951; Kannan and Ramani, 1978) and that in turn low sulfate concentrations in the soil promote molybdate uptake (Shinmachi etal., 2010) pioneered speculations on the nature of molybdate transporters. In fact, 
Table 1 | Components of molybdenum metabolism in higher plants (Arabidopsis thaliana).

\begin{tabular}{|c|c|c|}
\hline Protein names & Agi code & Known / proposed function \\
\hline MOT1/SULTR 5;2 & AT2G25680 & Molybdate transport \\
\hline MOT2/SULTR 5;1 & AT1G80310 & Molybdate transport / export from vacuole \\
\hline CNX1 & AT5G20990 & Moco biosynthesis step 3 \\
\hline CNX2 & AT2G31955 & Moco biosynthesis step 1 \\
\hline CNX3 & AT1G01290 & Moco biosynthesis step 1 \\
\hline CNX5 & AT5G55130 & Moco biosynthesis step 2 \\
\hline CNX6 & AT2G43760 & Moco biosynthesis step 2 \\
\hline CNX7 & AT4G10100 & Moco biosynthesis step 2 \\
\hline Nia1/NR1 & AT1G77760 & Nitrate reductase (minor form) \\
\hline $\mathrm{Nia} 2 / \mathrm{NR} 2$ & AT1G37130 & Nitrate reductase (main form) \\
\hline SO & AT3G01910 & Oxidation/elimination of cytotoxic sulfite \\
\hline mARC1/MOSC1 & AT5G44720 & $\begin{array}{l}\text { Unknown (reduction of } \mathrm{N} \text {-hydroxylated } \\
\text { compounds ?) }\end{array}$ \\
\hline mARC2/MOSC2 & AT1G30910 & $\begin{array}{l}\text { Unknown (reduction of } \mathrm{N} \text {-hydroxylated } \\
\text { compounds?) }\end{array}$ \\
\hline AAO1 & AT5G20960 & Unknown (IAA biosynthesis ?) \\
\hline $\mathrm{AAO} 2$ & AT3G43600 & Unknown (IAA biosynthesis ?) \\
\hline AAO3 & AT2G27150 & ABA biosynthesis \\
\hline $\mathrm{AAO} 4$ & AT1G04580 & Synthesis of benzoic acid \\
\hline AtXDH1 & AT4G34890 & Purine degradation \\
\hline AtXDH2 & AT4G34900 & Pseudogene? \\
\hline ABA3/LOS5 & AT1G16540 & $\begin{array}{l}\text { Mocosulfuration and activation of } \mathrm{AO} \text { and } \\
\mathrm{XDH} \text { proteins }\end{array}$ \\
\hline ATM3/АВCB25 & AT5G58270 & $\begin{array}{l}\text { Transporter involved in cytosolic Fe-S } \\
\text { assembly and Moco synthesis }\end{array}$ \\
\hline
\end{tabular}

sulfate and molybdate share a high degree of similarity as they both possess a double negative charge $\left(\mathrm{SO}_{4}{ }^{2-}, \mathrm{MoO}_{4}{ }^{2-}\right)$, are similar in size, and have tetrahedral structures. It was thus proposed that molybdate import and distribution are facilitated by sulfate transporters or related systems. The first identified molybdate-specific transporters from Chlamydomonas reinhardtii (Tejada-Jimenez et al., 2007) and Arabidopsis thaliana (Tomatsu etal., 2007; Baxter etal., 2008) indeed turned out to belong to the family of sulfate transporters, yet lacking the otherwise typical STAS domain essential for sulfate transport activity (Shibagaki and Grossman, 2006). Unfortunately, the two reports on the Arabidopsis transporter, referred to as MOT1, differ in the subcellular localization of the transporter with Tomatsu et al. (2007) primarily showing endomembrane localization and Baxter et al. (2008) reporting a mitochondrial localization. Ascribing a precise function to MOT1 is therefore difficult and it remains to be proven in future studies whether MOT1 is involved in the intraand/or the inter-cellular translocation of molybdate. In addition to MOT1, another molydate transporter of the sulfate transporter family, MOT2, has been identified in Arabidopsis (Gasber et al., 2011). MOT2 localizes to the vacuole and MOT2-deficient plants are characterized by accumulation of molybdenum in leaves and reduced molybdenum contents in seeds. Along with the finding that MOT2 transcripts accumulate in senescing leaves, this suggests a function of MOT2 in exporting stored molybdate from the vacuole into the cytosol for translocation into maturing seeds. Moreover, total molybdenum contents were found to correlate with the levels of Moco in wildtype and MOT2 mutant leaves, indicating plants adjust Moco synthesis to the cellular levels of molybdate.

Just recently a novel molybdate transporter, also denoted as MOT2, has been identified in Chlamydomonas (Tejada-Jiménez et al., 2011). In contrast to Arabidopsis MOT2 however, this transporter is a member of the major facilitator superfamily which is completely unrelated to the sulfate transporter family. It is tempting to speculate that the homolog of this transporter in higher plants represents the as yet unidentified transporter involved in the uptake of molybdate at the root:soil interface.

\section{MOLYBDENUM COFACTOR AND MOLYBDENUM-DEPENDENT ENZYMES}

The only process known to require molybdenum/molybdate directly by plants is the biosynthesis of Moco, which is initiated in mitochondria and finalized in the cytosol. However, a detailed description of Moco biosynthesis is out of the scope of this work and is comprehensively covered by Bittner and Mendel (2010) and Mendel (2013). Even though Moco biosynthesis is well understood only little knowledge exists about the genetic and enzymatic regulation of Moco biosynthesis in plants. For instance, it is largely unknown whether the expression levels of Moco synthesis genes are affected by molybdate, and whether the endogenous levels of Moco vary, e.g., during plant development or in response to stress conditions. The only available information in this respect concerns the expression of molybdenum metabolism-related genes in the Arabidopsis MOT1 mutant that was grown without additional molybdate supply to induce endogenous molybdate deficiency (Ide et al., 2011). In fact, the Moco biosynthesis genes CNX2 and CNX6 were demonstrated to be upregulated under molybdate deficiency, which was likewise true for the molybdo-enzymes NR1 and NR2, the Moco sulfurase ABA3 and the transporter MOT2. Apart from these genes, molybdate deficiency also affected the expression of many genes involved in transport, stress responses, signal tranduction and in the metabolisms of nitrogen, sulfur, and phosphate, but also the levels of amino acids, sugars, organic acids, and purine metabolites were significantly altered, indicating that molybdate nutrition has global impact on plants.

Among the molybdo-enzymes, nitrate reductase (NR) represents the cytosolic key enzyme of nitrogen assimilation that reduces nitrate to nitrite (Campbell, 2001). In addition to Moco, NR also depends on heme and FAD as prosthetic groups and strictly requires NADH or NADPH for enzymatic activity. A deficiency in NR results in the inability of the plant to mobilize nitrogen, which is inseparably associated with the loss of plant viability in the absence of alternative nitrogen sources. Under low-oxygen conditions, NR is capable of reducing nitrite to nitric oxide (NO), and NR-derived $\mathrm{NO}$ appears to be among the major sources of NO in plants with impact on plant development, protection against reactive oxygen species, phytoalexin accumulation, and pathogen resistance (Rockel et al., 2002). 


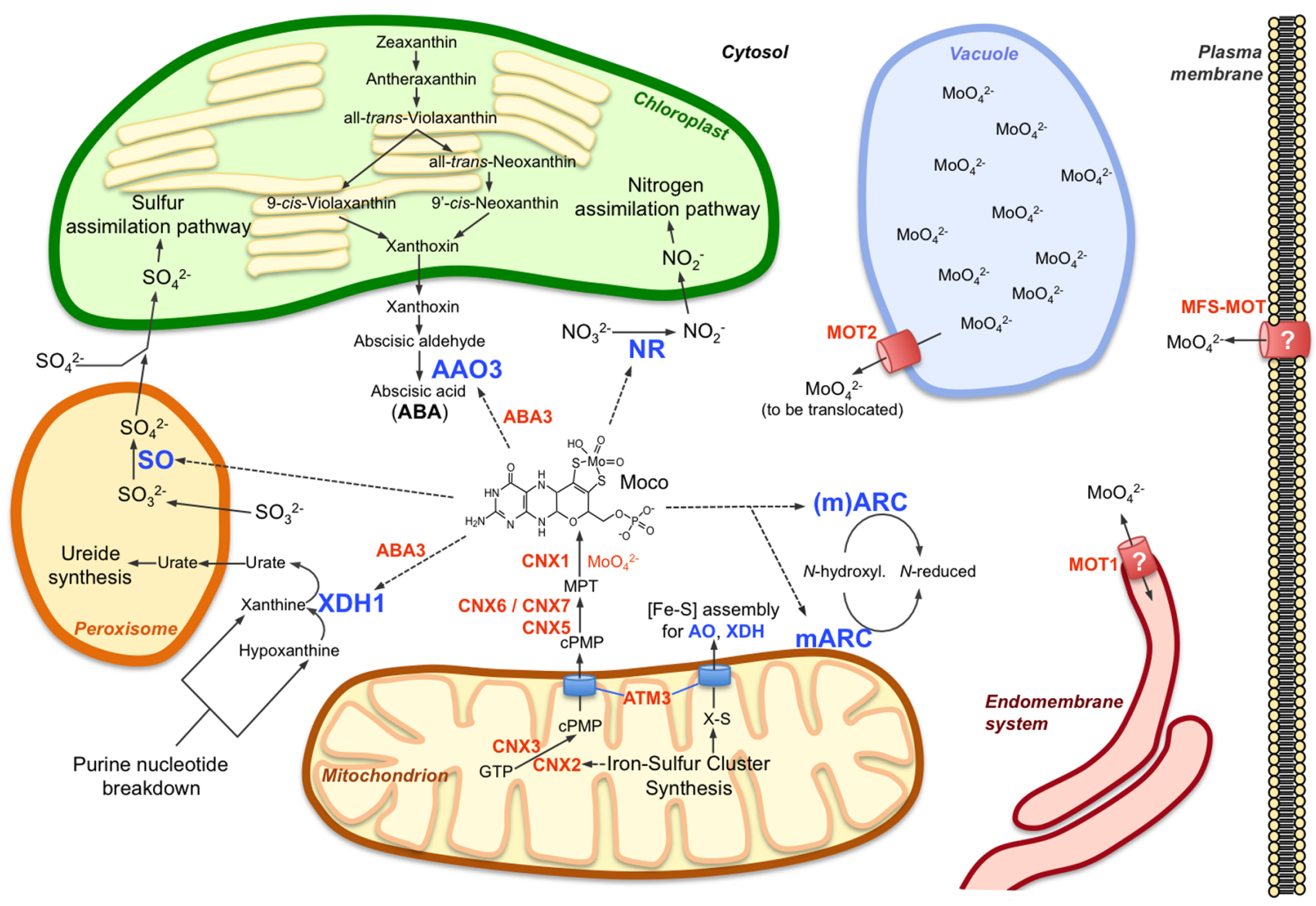

FIGURE 1 | Molybdenum metabolism in higher plant cells. The main components of molybdenum metabolism in plants are shown including the Moco biosynthetic pathway (CNX proteins) in mitochondria and cytosol, the Moco user enzymes and their respective main functions in nitrogen assimilation (NR), ABA synthesis (AAO3), purine catabolism (XDH1), and sulfite detoxification (SO). mARC enzymes are proposed to function in reduction of certain $\mathrm{N}$-hydroxylated substrates, which have not yet been identified. While one of the two mARC isoforms (mARC2) contains an $\mathrm{NH}_{2}$-terminal mitochondrial targeting sequence, such targeting sequence is absent at the second isoform, which therefore is assumed to act in the cytosol. In contrast to the molybdate transporter MOT2, which functions at the vacuolar membrane as a molybdate exporter, MOT1 might localize to the endomembrane system, possibly to the endoplasmic reticulum. A mitochondrial localization of MOT1 has also been reported but appears less likely as no obvious reason exists for import or export of molybdate into or out of the mitochondria, respectively. The plant homolog (MFS-MOT) of the major facilitator superfamily molybdate transporter MOT2 from Chlamydomonas might be required for molybdate import across the plasma membrane. The function of the Moco sulfurase ABA3 in activation of $A O$ and $X D H$ is indicated, just as the functions of the mitochondrial ABC transporter ATM3 in export of cPMP from mitochondria and in cytosolic iron-sulfur cluster ([Fe-S]) assembly for $\mathrm{AO}$ and $\mathrm{XDH}$ (and other extra-mitochondrial proteins). Further details are given in the main text and are reviewed by Bittner and Mendel (2010) and Mendel (2013). Molybdo-enzymes are indicated by blue letters, other components of molybdenum metabolism by orange letters; dotted arrows indicate requirement for Moco by molybdo-enzymes.
Plant sulfite oxidase (SO) is a peroxisomal enzyme (Nowak et al., 2004), which exclusively consists of a Moco-binding domain required for oxidizing sulfite to sulfate. In this process, substratederived electrons are transferred to molecular oxygen with formation of superoxide anions (Byrne et al., 2009) and hydrogen peroxides (Haensch etal., 2006). In the physiological context, SO represents a part of an intracellular sulfite homeostasis network required to prevent plant cells from the toxic effects of endogenously arising sulfite (Brychkova et al., 2007; Lang et al., 2007).

Xanthine dehydrogenase $(\mathrm{XDH})$ requires Moco, FAD, and two iron-sulfur clusters (Hille et al., 2011), and its main function is associated to purine degradation by oxidizing hypoxanthine to xanthine and xanthine to uric acid in the cytosol.
Electrons released from the substrate are preferably transferred to $\mathrm{NAD}^{+}$. At extremely low concentrations of $\mathrm{NAD}^{+}$, molecular oxygen can serve as alternative electron acceptor with simultaneous generation of superoxides (Hesberg et al., 2004; Yesbergenova etal., 2005; Zarepour etal., 2010). As indicated by $\mathrm{XDH}$-deficient plants, the function of $\mathrm{XDH}$ is crucial for plant growth, senescence, and fertility (Nakagawa et al., 2007; Brychkova et al., 2008). Independent from other substrates, XDH exhibits strong intrinsic NADH oxidase activity, which is accompanied by the use of oxygen as electron acceptor and simultaneous formation of superoxide anions (Yesbergenova etal., 2005; Zarepour etal., 2010). It is speculated that this activity is of importance in the response to biotic and abiotic stresses. 
Aldehyde oxidase (AO) has derived from XDH by gene duplication and neo-functionalization (Rodríguez-Trelles et al., 2003) and therefore shares catalytical and structural similarities with $\mathrm{XDH}$. In contrast to $\mathrm{XDH}$ however, $\mathrm{AO}$ proteins preferably oxidize aldehydes to the respective carboxylic acid. Moreover, molecular oxygen is the exclusive electron acceptor during catalysis and its consumption is obligatorily linked with the generation of hydrogen peroxide and superoxide anions (Yesbergenova et al., 2005; Zarepour et al., 2012). Obviously, the genome of most, if not all, plant species harbors several $\mathrm{AO}$ genes, which indicates a specific need of plants for several independent aldehyde oxidation activities. The number of $\mathrm{AO}$ proteins and their specific functions might therefore relate to the specific metabolic and environmental demands of different plant species. For instance, the Arabidopsis genome encodes the genes $A A O 1-A A O 4$ and the respective proteins form homo- and hetero-dimers with overlapping, but also distinct substrate specificities (Akaba et al., 1999; Koiwai et al., 2000; Seo et al., 2000a,b). The most important isoform is AAO3, which catalyzes the oxidation of abscisic aldehyde to abscisic acid (ABA) in the last cytosolic step of ABA synthesis. Due to the function of $A B A$ in many aspects of plant growth and development, and in adaptation to a variety of abiotic stresses, $A A O 3$-deficient plants with reduced $A B A$ levels are characterized by a high transpiration rate, reduced stress tolerance, and impaired seed dormancy (Seo and Koshiba, 2011). For AAO1 and AAO2, a function in one of the multiple biosynthesis routes of indole-3-acetic acid is suggested as they both efficiently catalyze the oxidation of indole acetaldehyde to indole-3-acetic acid in vitro. AAO4 is expressed preferably in siliques and catalyzes the oxidation of benzaldehyde into benzoic acid, the latter being incorporated into glucosinolates that likely serve as herbivore defense compounds (Ibdah et al., 2009).

The mitochondrial amidoxime reducing component (mARC) has been identified in mitochondria of mammals and catalyzes the reduction of $N$-hydroxylated substances (Havemeyer et al., 2011). Like mammals, plant genomes encode two mARC isoforms, which have not yet been investigated in detail. The physiological role of mARC proteins is therefore still enigmatic, even though previous studies in Chlamydomonas and on recombinant human proteins suggest a function in the detoxification of $\mathrm{N}$-hydroxylated base analogs (Chamizo-Ampudia et al., 2011; Krompholz et al., 2012) and/or in the regulation of L-arginine-dependent NO synthesis (Kotthaus et al., 2011).

Although the physiological functions of some molybdoenzymes are as yet not fully understood, it is obvious that others hold key positions in essential or at least important metabolic pathways. Any factor that affects one of these enzymes will thus also affect the respective pathway, with effects on Moco biosynthesis and molybdate supply resulting in the pleiotropic impairment of all molybdo-enzyme activities, associated with severe reduction of plant viability or even death of the plant.

\section{CROSSTALK BETWEEN MOLYBDENUM AND IRON METABOLISM}

An interrelation between molybdenum and iron has been reported by Berry and Reisenauer (1967) who found that molybdate supply significantly increases the capacity of tomato plants to absorb $\mathrm{Fe}^{2+}$. The inverse phenomenon, an influence of $\mathrm{Fe}^{2+}$ on molybdate uptake, has later been investigated in excised rice roots, which showed increased molybdate uptake capacity in the presence of $\mathrm{FeSO}_{4}$ (Kannan and Ramani, 1978). This interrelation was confirmed in an ionomics study involving irondeficient plants, in which molybdenum contents were shown to be reduced (Baxter, 2009). However, the link between the two metals in this approach is not fully understood and might be related either to acidification of the rhizosphere during irondeficiency, which would result in molybdenum becoming less available to the plant, or to down-regulation of MOT1, which might affect molybdate uptake. Interestingly, several key genes involved in molybdenum metabolism were found to respond to iron-deficiency in Arabidopsis roots with the MOT1 gene indeed showing down-regulation, and the genes $C N X 2, C N X 3$, and $A B A 3$ showing up-regulation (www.genevestigator.com). By contrast, under molybdate-deficient conditions as induced by Ide etal. (2011) none of the known key genes of iron uptake and transport such as FRO2, IRT1, or ferritins were found to be altered in expression. Instead, only the genes of the ferric-chelate reductases oxidases FRO6 and FRO7 and the iron-regulated protein IREG1 showed down-regulation. It can thus be assumed that iron availability is a crucial regulatory element for plant molybdenum metabolism, while molybdate availability is of subordinated importance for iron metabolism.

Apart from metal uptake and gene regulation, crosstalk between molybdenum and iron is observed on the levels of Moco biosynthesis and molybdo-enyzmes. As previously mentioned, some of the latter require iron-containing prosthetic groups such as ironsulfur clusters (AO and XDH) or heme (NR) besides Moco and FAD. Indeed, when looking in more detail on the more than 50 molybdo-enzymes known in all organisms, then the vast majority also depends on such iron-containing groups (Hille, 2013). It seems therefore reasonable to assume that this co-occurence of molybdenum and iron is due to the beneficial influence on each other's redox properties. In addition, the Moco biosynthesis enzyme CNX2 requires two [4Fe-4S] clusters for activity and the crosstalk between molybdenum and iron is further substantiated by the fact that $C N X 2$ gene expression is controlled by both, molybdate and iron availability.

Molybdenum and iron metabolisms also merge at the function of ATM3, a mitochondrial ABC-type transporter that is crucial for the maturation of extra-mitochondrial iron-sulfur proteins (Bernard et al., 2009; Balk and Pilon, 2011). ATM3 exports an as yet unknown sulfur-containing compound from the mitochondria into the cytosol, where this compound is used for assembly of iron-sulfur clusters. Surprisingly, ATM3 has been found to play an important role in enabling the export of the Moco biosynthesis intermediate cPMP from mitochondria into the cytosol as ATM3-deficient plants present reduced levels of Moco accompanied by increased cPMP levels in mitochondria (Teschner et al., 2010). Since the two molecules requiring ATM 3 for transport are likely to differ markedly, one can hypothesize that both are cotransported with glutathione, which has been speculated earlier to be a substrate of ATM3 (Kim et al., 2006) and to stimulate the activity of this type of transporter (Kuhnke et al., 2006).

Finally, an evolutionary overlap between molybdenum and iron metabolisms exists by the function of the Moco sulfurase ABA3, 
which is essentially required for the final activation of $\mathrm{AO}$ and $\mathrm{XDH}$. ABA3 is a two-domain protein with a $\mathrm{N}$-terminal L-cysteine desulfurase domain that decomposes L-cysteine to L-alanine and sulfur (Bittner et al., 2001; Heidenreich et al., 2005). The sulfur is bound as a persulfide to a strictly conserved cysteine residue of the protein $\left(\mathrm{ABA} 3-\mathrm{Cys}_{430} \mathrm{SH}+\underline{\mathrm{S}}^{2-}=>\mathrm{ABA}^{2}-\mathrm{Cys}{ }_{430} \mathrm{~S}-\underline{\mathrm{SH}}\right)$ and transferred to the Moco-binding $\mathrm{C}$-terminal domain (Wollers etal., 2008). On the C-terminal domain, the persulfide sulfur is transformed into a molybdenum-bound sulfido ligand by replacing an oxygen ligand $\left[\right.$ pterin- $\mathrm{MoO}_{2}(\mathrm{OH})+\underline{\mathrm{S}}^{2-}=>$ pterin$\left.\operatorname{MoO} \underline{S}(\mathrm{OH})+\mathrm{O}^{2-}\right]$. With receiving this type of Moco, the target proteins of $\mathrm{ABA} 3, \mathrm{AO}$, and $\mathrm{XDH}$, finally gain activity. Interestingly, L-cysteine desulfurases originated from the more ancient iron-sulfur cluster biosynthesis, in which they abstract sulfur from L-cysteine and deliver it to various scaffold proteins, onto which iron-sulfur clusters are assembled prior to insertion into apoenzymes (Lill etal., 2012). In case of ABA3 and its orthologs however, a cysteine desulfurase must have been fused to a selected scaffold to evolve into a new activator protein highly specific and exclusive for $\mathrm{AO}$ and $\mathrm{XDH}$.

Recently, an interesting observation has been made concerning the effect of sulfur supply on $\mathrm{AO}$ and $\mathrm{XDH}$ proteins (Cao et al., 2013). In this work, sulfate deficiency has been found to impair endogenous cysteine levels and simultaneously, the biosynthesis of the phytohormone ABA. This effect has been ascribed to reduced activity of $\mathrm{AAO} 3$ and it was concluded that $\mathrm{AAO} 3$, and in addition also $\mathrm{XDH}$, cannot properly be sulfurated by the Moco sulfurase ABA3 due to the limited availability of its substrate L-cysteine. This might indeed be one possible explanation for reduced activities of $\mathrm{AO}$ and $\mathrm{XDH}$ proteins in sulfate-deprived plants; yet, an effect on the biosynthesis of iron-sulfur clusters as required by $\mathrm{AO}$ and $\mathrm{XDH}$ proteins appears even more likely due to the higher demand of this process for L-cysteine (Forieri et al., 2013). As sulfur is embedded into molybdenum metabolism also at several other steps (e.g., Moco synthesis, sulfite detoxification, molybdate uptake), the three nutrients molybdenum, iron and sulfur appear to interact closely on various levels within a common metabolic network that needs to be elucidated in future studies.

\section{CONCLUSIONS AND PERSPECTIVES}

Many players in the molybdenum homeostasis network have meanwhile been identified and characterized with the enzymes of Moco synthesis and the molybdo-enzymes representing the most intensively-studied topics, even though also here many aspects still remain to be solved. Understanding of the function of molybdate transporters has just begun and a lot more effort needs to be invested to depict the import and export routes in plants and to identify the candidate(s) responsible for uptake of molybdate at the root:soil interface. A point, which has not been considered before is whether molybdate-binding and/or -storage proteins exist in plants that might shuttle molybdate between organelles and tissues or store it for specific requirements, respectively. Moreover, very little is known about factors controlling the expression of genes and interaction of proteins involved in molybdenum homeostasis, thus requiring further in-depth analysis on the transcriptome, proteome, interactome, metabolome, and ionome level.

\section{ACKNOWLEDGMENT}

This work was supported by the Deutsche Forschungsgemeinschaft (Bi 1075/3-2) which is gratefully acknowledged.

\section{REFERENCES}

Akaba, S., Seo, M., Dohmae, N., Takio, K., Sekimoto, H., Kamiya, Y., et al. (1999). Production of homo- and hetero-dimeric isozymes from two aldehyde oxidase genes of Arabidopsis thaliana. J. Biochem. 126, 395-401.

Balk, J., and Pilon, M. (2011). Ancient and essential: the assembly of iron-sulfur clusters in plants. Trends Plant Sci. 16, 218-226. doi: 10.1016/j.tplants.2010.12.006 Baxter, I. (2009). Ionomics: studying the social network of mineral nutrients. Curr. Opin. Plant Biol. 12, 381-386. doi: 10.1016/j.pbi.2009.05.002

Baxter, I., Muthukumar, B., Park, H. C., Buchner, P., Lahner, B., Danku, J., et al. (2008). Variation in molybdenum content across broadly distributed populations of Arabidopsis thaliana is controlled by a mitochondrial molybdenum transporter (MOT1). PLoS Genet. 4:e1000004. doi: 10.1371/journal.pgen.1000004

Bernard, D. G., Cheng, Y., Zhao, Y., and Balk, J. (2009). An allelic mutant series of ATM3 reveals its key role in the biogenesis of cytosolic iron-sulfur proteins in Arabidopsis. Plant Physiol. 151, 590-602. doi: 10.1104/pp.109.143651

Berry, J. A., and Reisenauer, H. M. (1967). The influence of molybdenum on iron nutrition of tomato. Plant Soil 27, 303-313.

Bittner, F., and Mendel, R. R. (2010). "Cell Biology of Molybdenum," in Cell Biology of Metals and Nutrients, eds. R. Hell and R. R. Mendel (Springer-Verlag Berlin Heidelberg 2010), Plant Cell Monogr. 17, 119-143. doi: 10.1007/978-3642-10613-2_6

Bittner, F., Oreb, M., and Mendel, R. R. (2001). ABA3 is a molybdenum cofactor sulfurase required for activation of aldehyde oxidase and xanthine dehydrogenase in Arabidopsis thaliana. J. Biol. Chem. 276, 40381-40384. doi: 10.1074/jbc.C100472200

Brychkova, G., Alikulov, Z., Fluhr, R., and Sagi, M. (2008). A critical role for ureides in dark and senescence-induced purine remobilization is unmasked in the Atxdh1 Arabidopsis mutant. Plant J. 54, 496-509. doi: 10.1111/j.1365-313X.2008. 03440.x

Brychkova, G., Xia, Z., Yang, G., Yesbergenova, Z., Zhang, Z., Davydov, O., et al. (2007). Sulfite oxidase protects plants against sulfur dioxide toxicity. Plant J. 50, 696-709. doi: 10.1111/j.1365-313X.2007.03080.x

Byrne, R. S., Haensch, R., Mendel, R. R., and Hille, R. (2009). Oxidative half-reaction of Arabidopsis thaliana sulfite oxidase: generation of superoxide by a peroxisomal enzyme. J. Biol. Chem. 284, 35479-35484. doi: 10.1074/jbc.M109.067355

Campbell, W. H. (2001). Structure and function of eukaryotic NAD(P)H:nitrate reductase. Cell Mol. Life Sci. 58,194-204. doi: 10.1007/PL00000847

Cao, M. J., Wang, Z., Zhao, Q., Mao, J. L., Speiser, A., Wirtz, M., et al. (2013). Sulfate availability affects ABA levels and germination response to ABA and salt stress in Arabidopsis thaliana. Plant J. doi: 10.1111/tpj.12407[Epub ahead of Print].

Chamizo-Ampudia, A., Galvan, A., Fernandez, E., and Llamas, A. (2011). The Chlamydomonas reinhardtii molybdenum cofactor enzyme crARC has a $\mathrm{Zn}$ dependent activity and protein partners similar to those of its human homologue. Eukaryot. Cell 10, 1270-1282. doi: 10.1128/EC.05096-11

Forieri, I., Wirtz, M., and Hell, R. (2013). Toward new perspectives on the interaction of iron and sulfur metabolism in plants. Front. Plant Sci. 4:357. doi: 10.3389/fpls.2013.00357.

Gasber, A., Klaumann, S., Trentmann, O., Trampczynska, A., Clemens, S., Schneider, S., et al. (2011). Identification of an Arabidopsis solute carrier critical for intracellular transport and inter-organ allocation of molybdate. Plant Biol. (Stuttg). 13, 710-718. doi: 10.1111/j.1438-8677.2011.00448.x

Haensch, R., Lang, C., Riebeseel, E., Lindigkeit, R., Gessler, A., Rennenberg, H., et al. (2006). Plant sulfite oxidase as novel producer of H2O2: combination of enzyme catalysis with a subsequent non-enzymatic reaction step. J. Biol. Chem. 281, 6884-6888. doi: 10.1074/jbc.M513054200

Havemeyer, A., Lang, J., and Clement, B. (2011). The fourth mammalian molybdenum enzyme mARC: current state of research. Drug Metab. Rev. 43, 524-539. doi: $10.3109 / 03602532.2011 .608682$

Heidenreich, T., Wollers, S., Mendel, R. R., and Bittner, F. (2005). Characterization of the NifS-like domain of ABA3 from Arabidopsis thaliana provides insight into the mechanism of molybdenum cofactor sulfuration. J. Biol. Chem. 280, 4213-4218. doi: 10.1074/jbc.M411195200

Hesberg, C., Haensch, R., Mendel, R. R., and Bittner, F. (2004). Tandem orientation of duplicated xanthine dehydrogenase genes from Arabidopsis thaliana: 
differential gene expression and enzyme activities. J. Biol. Chem. 279, 13547 13554. doi: 10.1074/jbc.M312929200

Hille, R. (2013). The molybdenum oxotransferases and related enzymes. Dalton Trans. 42, 3029-3042. doi: 10.1039/c2dt32376a

Hille, R., Nishino, T., and Bittner, F. (2011). Molybdenum enzymes in higher organisms. Coord. Chem. Rev. 255, 1179-1205. doi: 10.1016/j.ccr.2010.11.034

Hu, Y., and Ribbe, M. W. (2013). Nitrogenase assembly. Biochim. Biophys. Acta 1827, 1112-1122. doi: 10.1016/j.bbabio.2012.12.001

Ibdah, M., Chen, Y.T., Wilkerson, C.G., and Pichersky, E. (2009). An aldehyde oxidase in developing seeds of Arabidopsis converts benzaldehyde to benzoic acid. Plant Physiol. 150, 416-423. doi: 10.1104/pp.109.135848

Ide, Y., Kusano, M., Oikawa, A., Fukushima, A., Tomatsu, H., Saito, K., et al. (2011). Effects of molybdenum deficiency and defects in molybdate transporter MOT1 on transcript accumulation and nitrogen/sulphur metabolism in Arabidopsis thaliana. J. Exp. Bot. 62, 1483-1497. doi: 10.1093/jxb/erq345

Kaiser, B. N., Gridley, K. L., Ngaire Brady, J., Phillips, T., and Tyerman, S. D. (2005) The role of molybdenum in agricultural plant production. Ann. Bot. 96, 745-754 doi: 10.1093/aob/mci226

Kannan, S., and Ramani, S. (1978). Studies on molybdenum absorption and transport in bean and rice. Plant Physiol. 62, 179-181. doi: 10.1104/pp.62.2.179

Kim, D. Y., Bovet, L., Kushnir, S., Noh, E. W., Martinoia, E., and Lee, Y. (2006). AtATM3 is involved in heavy metal resistance in Arabidopsis. Plant Physiol. 140, 922-932. doi: 10.1104/pp.105.074146

Kneip, C., Lockhart, P., Voss, C., and Maier, U. G. (2007). Nitrogen fixation in eukaryotes-new models for symbiosis. BMC Evol. Biol. 7:55. doi: 10.1186/14712148-7-55

Koiwai, H., Akaba, S., Seo, M., Komano, T., and Koshiba, T. (2000). Functional expression of two Arabidopsis aldehyde oxidases in the yeast Pichia pastoris. $J$ Biochem. 127, 659-664.

Kotthaus, J., Wahl, B., Havemeyer, A., Kotthaus, J., Schade, D., Garbe-Schoenberg, D., et al. (2011). Reduction of $\mathrm{N}(\omega)$-hydroxy-L-arginine by the mitochondrial amidoxime reducing component (mARC). Biochem. J. 433, 383-391. doi 10.1042/BJ20100960

Krompholz, N., Krischkowski, C., Reichmann, D., Garbe-Schoenberg, D., Mendel, R. R., Bittner, F., et al. (2012). The mitochondrial amidoxime reducing component (mARC) is involved in detoxification of N-hydroxylated base analogues. Chem. Res. Toxicol. 25, 2443-2450. doi: 10.1021/tx300298m

Kuhnke, G., Neumann, K., Muehlenhoff, U., and Lill, R. (2006). Stimulation of the ATPase activity of the yeast mitochondrial ABC transporter Atmlp by thiol compounds. Mol. Membr. Biol. 23, 173-184.

Kumchai, J., Huang, J. Z., Lee, C. Y., Chen, F. C., and Chin, S. W. (2013). Proline partially overcomes excess molybdenum toxicity in cabbage seedlings grown in vitro. Genet. Mol. Res. 12, 5589-5601. doi: 10.4238/2013.November.18.8

Lang, C., Popko, J., Wirtz, M., Hell, R., Herschbach, C., Kreuzwieser, J., et al. (2007). Sulfite oxidase as key enzyme for protecting plants against sulfur dioxide. Plant Cell Environ. 30, 447-455. doi: 10.1111/j.1365-3040.2006.01632.x

Lill, R., Hoffmann, B., Molik, S., Pierik, A. J., Rietzschel, N., Stehling, O., etal. (2012). The role of mitochondria in cellular iron-sulfur protein biogenesis and iron metabolism. Biochim. Biophys. Acta 1823, 1491-1508. doi: 10.1016/j.bbamcr.2012.05.009

Mendel, R. R. (2013). The molybdenum cofactor. J. Biol. Chem. 288, 13165-13172. doi: 10.1074/jbc.R113.455311

Nakagawa, A., Sakamoto, S., Takahashi, M., Morikawa, H., and Sakamoto, A. (2007). The RNAi-mediated silencing of xanthine dehydrogenase impairs growth and fertility and accelerates leaf senescence in transgenic Arabidopsis plants. Plant Cell Physiol. 48, 1484-1495. doi: 10.1093/pcp/pcm119

Nowak, K., Luniak, N., Witt, C., Wuestefeld, Y., Wachter, A., Mendel, R. R., et al. (2004). Peroxisomal localization of sulfite oxidase separates it from chloroplast-based sulfur assimilation. Plant Cell Physiol. 45, 1889-1894. doi: $10.1093 / \mathrm{pcp} / \mathrm{pch} 212$

Rockel, P., Strube, F., Rockel, A., Wildt, J., and Kaiser, W. M. (2002). Regulation of nitric oxide (NO) production by plant nitrate reductase in vivo and in vitro. $J$. Exp. Bot. 53, 103-110. doi: 10.1093/jexbot/53.366.103

Rodríguez-Trelles, F., Tarrío, R., and Ayala, F. J. (2003). Convergent neofunctionalization by positive darwinian selection after ancient recurrent duplications of the xanthine dehydrogenase gene. Proc. Natl. Acad. Sci. U.S.A. 100, 13413-13417. doi: $10.1073 /$ pnas. 1835646100
Seo, M., Koiwai, H., Akaba, S., Komano, T., Oritani, T., Kamiya, Y., et al. (2000a) Abscisic aldehyde oxidase in leaves of Arabidopsis thaliana. Plant J. 23, 481-488. doi: 10.1046/j.1365-313x.2000.00812.x

Seo, M., Peeters, A. J., Koiwai, H., Oritani, T., Marion-Poll, A., Zeevaart, J. A., et al. (2000b). The Arabidopsis aldehyde oxidase 3 (AAO3) gene product catalyzes the final step in abscisic acid biosynthesis in leaves. Proc. Natl. Acad. Sci. U.S.A. 97, 12908-12913. doi: 10.1073/pnas.220426197

Seo, M., and Koshiba, T. (2011). Transport of ABA from the site of biosynthesis to the site of action. J. Plant Res. 124, 501-507. doi: 10.1007/s10265-011-0411-4

Shibagaki, N., and Grossman, A. R. (2006). The role of the STAS domain in the function and biogenesis of a sulfate transporter as probed by random mutagenesis. J. Biol. Chem. 281, 22964-22973. doi: 10.1074/jbc.M603462200

Shinmachi, F., Buchner, P., Stroud, J. L., Parmar, S., Zhao, F. J., McGrath, S. P., et al. (2010). Influence of sulfur deficiency on the expression of specific sulfate transporters and the distribution of sulfur, selenium, and molybdenum in wheat. Plant Physiol. 153, 327-336. doi: 10.1104/pp.110.153759

Stout, P. R., Meagher, W. R., Pearson, G. A., and Johnson, C. M. (1951). Molybdenum nutrition of crop plants. I. The influence of phosphate and sulfate on the absorption of molybdenum from soils and solution cultures. Plant Soil 3, 51-87. Tejada-Jiménez, M., Galván, A., and Fernández, E. (2011). Algae and humans share a molybdate transporter. Proc. Natl. Acad. Sci. U.S.A. 108, 6420-6425. doi: 10.1073/pnas. 1100700108

Tejada-Jimenez, M., Llamas, A., Sanz-Luque, E., Galvan, A., and Fernandez, E. (2007). A high-affinity molybdate transporter in eukaryotes. Proc. Natl. Acad. Sci. U.S.A. 104, 20126-20130. doi: 10.1073/pnas.0704646104

Teschner, J., Lachmann, N., Geisler, M., Selbach, K., Balk, J., Mendel, R. R., et al. (2010). A novel role for mitochondrial ABC transporter ATM3 from Arabidopsis in molybdenum cofactor biosynthesis. Plant Cell 22, 468-480. doi: 10.1105/tpc.109.068478

Tomatsu, H., Takano, J., Takahashi, H., Watanabe-Takahashi, A., Shibagaki, N., and Fujiwara, T. (2007). An Arabidopsis thaliana high-affinity molybdate transporter required for efficient uptake of molybdate from soil. Proc. Natl. Acad. Sci. U.S.A. 104, 18807-18812. doi: 10.1073/pnas.070637310

Wollers, S., Heidenreich, T., Zarepour, M., Zachmann, D., Kraft, C., Zhao, Y., et al. (2008). Binding of sulfurated molybdenum cofactor to the C-terminal domain of ABA3 from Arabidopsis thaliana provides insight into the mechanism of molybdenum cofactor sulfuration. J. Biol. Chem. 283, 9642-9650. doi: 10.1074/jbc.M708549200

Yesbergenova, Z., Yang, G., Oron, E., Soffer, D., Fluhr, R., and Sagi, M. (2005). The plant Mo-hydroxylases aldehyde oxidase and xanthine dehydrogenase have distinct reactive oxygen species signatures and are induced by drought and abscisic acid. Plant J. 42, 862-876. doi: 10.1111/j.1365-313X.2005.02422.x

Zarepour, M., Kaspari, K., Stagge, S., Rethmeier, R., Mendel, R. R., and Bittner, F. (2010). Xanthine dehydrogenase AtXDH1 from Arabidopsis thaliana is a potent producer of superoxide anions via its NADH oxidase activity. Plant Mol. Biol. 72, 301-310. doi: 10.1007/s11103-009-9570-2

Zarepour, M., Simon, K., Wilch, M., Nielaender, U., Koshiba, T., Seo, M., et al. (2012). Identification of superoxide production by Arabidopsis thaliana aldehyde oxidases AAO1 and AAO3. Plant Mol. Biol. 80, 659-671. doi: 10.1007/s11103012-9975-1

Conflict of Interest Statement: The authors declare that the research was conducted in the absence of any commercial or financial relationships that could be construed as a potential conflict of interest.

Received: 29 November 2013; accepted: 22 January 2014; published online: 07 February 2014.

Citation: Bittner F (2014) Molybdenum metabolism in plants and crosstalk to iron. Front. Plant Sci. 5:28. doi: 10.3389/fpls.2014.00028

This article was submitted to Plant Nutrition, a section of the journal Frontiers in Plant Science.

Copyright $(0) 2014$ Bittner. This is an open-access article distributed under the terms of the Creative Commons Attribution License (CC BY). The use, distribution or reproduction in other forums is permitted, provided the original author(s) or licensor are credited and that the original publication in this journal is cited, in accordance with accepted academic practice. No use, distribution or reproduction is permitted which does not comply with these terms. 